\title{
ARGUMENTAÇÃO E APRENDIZAGEM DA ESCRITA NA ESCOLA
}

\author{
Cecília Maria Aldigueri Goulart ${ }^{i}$
}

Resumo: A relação entre discurso e argumentação é a base para o postulado que se constitui em eixo do artigo - enunciar é argumentar, tomando como perspectiva a teoria da enunciação de Bakhtin. O diálogo é entendido como o movimento e o método de constituição dos discursos. Nesta direção, a categoria linguagens sociais tem sido chave para considerar como argumentativo o movimento enunciativo do discurso de diferentes áreas de conhecimento. As linguagens sociais são concebidas como modos de estruturação dos saberes destas áreas. O objetivo do artigo é observar e discutir na produção de textos escritos por crianças em processo de alfabetização marcas da aprendizagem de diferentes argumentações dependentes da linguagem social utilizada. Modos de ensinar a escrita também se mostram pertinentes à discussão.

Palavras-chave: Argumentação. Produção de textos. Linguagens sociais. Escola.

Abstract: The relationship between discourse and argumentation is the basis for the assumption that enunciating is arguing, taking the Bakhtinian theoretical perspective as reference. Dialogism is seen both as movement and as the method of constituting discourses. Thus, the category social languages has been key in considering as argumentative the enunciative movement of discourses in different fields of knowledge, insofar as these social languages are conceived as structural forms that organize knowledge in these areas, such as Science, History, and so on. The aim of this paper is to observe and discuss, through the analysis of written texts produced by seven years old children in the process of literacy, the markers of the learning of different argumentations dependent upon the social language used. A discursive approach of the teaching and learning process of the school written language is also relevant to the discussion.

Keywords: Argumentation. Production of written text. Social languages. School.

i Doutora em Letras pela Pontifícia Universidade Católica do Rio de Janeiro (PUC-Rio). Professora Titular da Universidade Federal Fluminense (UFF), membro do Programa de Pós-Graduação em Educação da mesma instituição. E-mail: goulartcecilia@uol.com.br. 
EID\&A - Revista Eletrônica de Estudos Integrados em Discurso e Argumentação, Ilhéus, n. 12, jul/dez.2016.

\section{Introdução}

Um dos braços de nosso estudo tem sido os processos de aprendizagem da escrita na escola. Nos movimentos dessa aprendizagem, as crianças estão ampliando e aprofundando visões de mundo, alargando horizontes de sentido. O caminho da investigação vem sendo trilhado com base na teoria da enunciação de Bakhtin, sendo que uma de suas facetas se constitui com o pressuposto de que enunciar é argumentar (GOULART, 2005, 2007, 2009, 2010, 2011), embora o autor não tenha se manifestado especificamente sobre este tema. Entendemos que as crianças ao aprenderem a enunciar por escrito estão desenvolvendo novas formas de argumentar, características dos espaços sociais em que são criadas, compondo aspectos da chamada cultura escrita.

No contexto da escola, a aula, como espaço de produção de conhecimentos, é considerada, exploratoriamente, como um gênero do discurso, já que nesse evento existe certa organização discursiva estabilizada, que é condicionada e determinada pelo tempo e pelo espaço. Conforme Bakhtin, "toda situação inscrita duravelmente nos costumes possui um auditório organizado de uma certa maneira e consequentemente um certo repertório de pequenas fórmulas correntes" (1988, p. 126). Na aula, criação social inscrita na cultura, ao lado de intenções e propósitos definidos, também se observa um repertório de gestos e procedimentos pensado em função de certo auditório de pessoas, os alunos. E observam-se instabilidades, surpresas nos enunciados, dado que, assim como os sujeitos que lá interagem, a realidade e a língua são vivas e movediças.

Cada enunciado é um elo da cadeia complexa de outros enunciados, segundo Bakhtin. De um lado, o enunciado do locutor que já contém o germe da resposta; de outro, o processo de compreensão de enunciados, envolvendo a orientação do ouvinte em relação àquela resposta, contextualizando-a, levando-o a produzir contrapalavras ao enunciado do locutor. É precisamente nesse sentido que entendemos a enunciação como forma de ação na direção do outro, como forma de argumentar. Não só compreendemos a significação da palavra enquanto palavra da língua, também adotamos para com ela uma atitude responsiva ativa (simpatia, concordância, discordância, estímulo à ação), como destaca Bakhtin: "[...] Ao escolher a palavra, partimos das intenções que presidem ao todo do nosso enunciado" (BAKHTIN, 1992, p. 310, grifos nossos). 
EID\&A - Revista Eletrônica de Estudos Integrados em Discurso e Argumentação, Ilhéus, n. 12, jul/dez.2016.

Na perspectiva assumida por nós, a argumentação está enraizada na construção dos signos, dos gêneros do discurso e das linguagens sociais na medida em que, quando nos apropriamos de palavras dos outros, apropriamonos também do tom apreciativo, isto é, das condições sociais em que são produzidas e têm valor. A argumentatividade da linguagem é, nesta proposta, inerente ao princípio dialógico. O ouvinte é aquele para quem o discurso é orientado e que intrinsecamente determina a estrutura do discurso. $O$ ouvinte exerce influência crucial sobre todos os fatores do discurso.

\begin{abstract}
Nossa transformação ideológica é justamente um conflito tenso no nosso interior pela supremacia dos diferentes pontos de vista verbais e ideológicos, aproximações, tendências, avaliações. A estrutura semântica da palavra internamente persuasiva não é terminada, permanece aberta, é capaz de revelar sempre todas as novas possibilidades semânticas em cada um dos seus novos contextos dialogizados (BAKHTIN, 1998, p. 146).
\end{abstract}

Morrison (1995, p. 169) estudou mudanças históricas que aconteceram na estrutura textual, e destacou que tais mudanças formaram um conhecimento social relacionado a argumentações históricas e filosóficas, ligadas às necessidades de ramos particulares do conhecimento. Com base no estudo deste autor observamos que as diferentes áreas de saber foram, ao longo do tempo histórico, instituindo formas de expor seus conhecimentos, elaborando diferentes textualidades, que estamos considerando como diferentes modos de argumentar. Diz Stock (1983, p. 62 apud Morrison 1995, p. 169): "os homens começam a pensar os fatos não como registrados pelos textos, mas como incorporados neles". Ou seja, os modos de enunciar passam a integrar os conhecimentos incorporados.

Como compreender processos argumentativos em sala de aula com base na teoria da enunciação de Bakhtin? Como crianças em processo de alfabetização na escola, entendido com ampliação da leitura de mundo, em que se aprendem conhecimentos de diferentes áreas, explicitam por escrito novas linguagens sociais (da Ciência, da História, no nosso caso) que estão em processo de aprender? Esta é a direção que temos estudado e explorado, buscando possibilidades teórico-metodológicas para enfrentar o tema; neste movimento, o presente artigo foi elaborado. 
EID\&A - Revista Eletrônica de Estudos Integrados em Discurso e Argumentação, Ilhéus, n. 12, jul/dez.2016.

\section{Aprendendo a escrever produzindo textos}

Sabemos que a seleção de palavras dos enunciados é realizada a partir das intenções que presidem o seu todo. A situação social mais imediata e o meio social mais amplo determinam a estrutura da enunciação, em que as palavras são orientadas em função do interlocutor, do auditório social. É possível que as crianças aprendam a produzir textos na escola enquanto se alfabetizam? Como isto se dá? Embora o título da seção possa parecer redundante e óbvio, de um modo geral as pessoas não se alfabetizam escrevendo textos. Alfabetizam-se decompondo e compondo palavras e frases em unidades linguísticas menores, como fonemas, letras e sílabas, colocando em segundo plano a dimensão do sentido. No caso da escola em que estudam as crianças cujos textos são apresentados, entretanto, elas são instigadas a ler e a escrever textos, da maneira como podem e sabem.

Feito o destaque, apresentamos as premissas iniciais que sustentam o estudo que vem sendo realizado (GOULART, 2007): (1) a argumentatividade da linguagem é inerente ao princípio dialógico, uma vez que todo enunciado é produzido intencionalmente na direção do outro, no movimento da interminável cadeia de enunciações; (2) enunciar é agir sobre o outro, o interlocutor, assim enunciar extrapola a ideia de compreender e responder enunciados.

Compondo o cenário teórico, o conceito de linguagens sociais tem sido valioso para a nossa reflexão. Segundo Bakhtin, ao lado da organização da língua em gêneros, se entrelaça, ora coincidindo ora divergindo, o que o autor define como linguagens sociais: "são pontos de vista específicos sobre o mundo, formas da sua interpretação verbal, perspectivas específicas objetais, semânticas e axiológicas" (BAKHTIN, 1998, p. 98). Elas são carregadas de conteúdos determinados, que as especificam, implicando, além de vocabulário, formas de orientação intencional de interpretação, com direções definidas, impregnadas de apreciações concretas, ao unirem-se a objetos, a áreas de conhecimento e a gêneros.

Há distinções metodológicas nas linguagens sociais: orientam-se por princípios básicos de seleção e constituição diversos, e sua constituição guiase por princípios orientadores funcionais, de conteúdo temático ou ainda sócio-dialetológico. Ou seja, as linguagens sociais organizam-se, atendendo a necessidades de grupos sociais, cumprindo funções específicas, conformando 
EID\&A - Revista Eletrônica de Estudos Integrados em Discurso e Argumentação, Ilhéus, n. 12, jul/dez.2016.

esferas de conhecimento e expressando diferenças históricas e culturais entre aqueles grupos (BAKHTIN, 1998).

De acordo com o modo como concebemos nosso objeto de estudo, conforme já mencionado, a argumentação está enraizada na construção dos signos, dos gêneros do discurso e das linguagens sociais. Quando nos apropriamos de palavras dos outros nos processos enunciativos, apropriamonos também do tom apreciativo, isto é, das condições sociais em que são produzidas e que têm valor, como processos argumentativos.

Na perspectiva da prática pedagógica, entendemos que o processo de ensino-aprendizagem das disciplinas escolares possa ser dificultado pelo distanciamento entre as textualidades características das linguagens sociais do cotidiano e as textualidades das linguagens sociais trabalhadas na escola. As referências culturais do cotidiano dos alunos envolvem interpretações axiologicamente instituídas, compreendem modos de argumentar, ou seja, modos de ação na direção dos outros, que têm características composicionais muitas vezes diversas das linguagens sociais trabalhadas na escola.

\section{Avançando na compreensão de que enunciar é argumentar}

Em Goulart (2009), chegamos a dois eixos importantes para dar clareza e consistência à construção que vínhamos elaborando. O primeiro diz respeito ao foco da argumentação. Tradicionalmente, estuda-se a argumentação na língua, ou seja, a partir de recursos linguísticos para a caracterização de argumentos e processos argumentativos. No nosso caso, voltamo-nos para a argumentação que se constrói nos processos discursivos, nos modos como os enunciados e seus sentidos se produzem nas situações discursivas e nos processos de produção de linguagem.

O segundo eixo se organiza em torno do conceito de dialogismo, como epistemologia, com base em Holquist (1990, p. 33-39). Nesta concepção, tese e antítese não se mostram compatíveis com esse modo de pensar o discurso. O dialogismo é pensado como método e movimento ao mesmo tempo. Um movimento de circulação de sentidos, discursos que se encontram, polemizam, contrapõem-se, fortalecem-se etc. Bakhtin afirma que toda elocução concreta de um sujeito que fala põe em ação tanto forças centrífugas quanto forças centrípetas (BAKHTIN, 1981, p. 272). 
EID\&A - Revista Eletrônica de Estudos Integrados em Discurso e Argumentação, Ilhéus, n. 12, jul/dez.2016.

O confronto de discursos constitui o caráter da exterioridade da linguagem, e é essa exterioridade, de ordem discursiva, que determina a orientação argumentativa. A produção linguística afetada pela exterioridade constitui a argumentação. A análise nos coloca no espaço tenso em que a linguagem, no que ela tem de reguladora, constitui sentidos que, mais do que descrever o mundo, constituem os modos de sua apreensão, a sua orientação.

No intuito de aprofundar a compreensão do conceito de linguagens sociais em relação aos modos de argumentar, as concebemos como modos de estruturação dos saberes de diferentes campos do conhecimento, diferenciando-as de gêneros do discurso, entendidos como modos de construção dos dizeres. Construções discursivas são consideradas argumentações na medida em que são orientadas por projetos enunciativos que ordenam e tipificam os conhecimentos de determinadas maneiras, elaboradas na convergência e divergência de variados pontos de vista e visões de mundo. Na escola, em geral, são transmitidas como palavras de autoridade pelo apagamento que se efetua dos embates e dos processos que levam a estabilizarem os conhecimentos de determinadas formas.

Bakhtin (2004), tratando dos modos de trabalhar a estilística das formas gramaticais, afirma que a escolha entre dois modos de dizer não é determinada gramaticalmente, mas por puras considerações estilísticas, isto é, pela representativa e expressiva eficácia dessas formas. No processo de aprender a escrever, então, pode-se saber que a utilização de formas composicionais diferentes leva a ênfases diferentes no discurso. Assim, concordamos com Possenti (2001, p. 17) ao afirmar que a escolha é um efeito da multiplicidade dos recursos que competem entre si a todo instante. Escolher não é um ato de liberdade, mas o efeito de uma inscrição (seja genérica, social, discursiva), é efeito de exigências enunciativas, e não de personalidade ou de caracterologia.

3. Contribuições de Augusto Ponzio (2012), em conversa com Susan Petrilli e Massimo Bonfatini

Ponzio inicia a conversa com Petrilli e Bonfatini distinguindo os significados de argumentação e de retórica, destacando que a retórica oferece sentido não para contemplar, escolher e discutir, mas para consumir. Diz o autor que a retórica é prazerosa e consola, porque defende a 'manutenção das crenças e dos hábitos'. Vincula-se, assim, a estereótipos, no 
EID\&A - Revista Eletrônica de Estudos Integrados em Discurso e Argumentação, Ilhéus, n. 12, jul/dez.2016.

empacotamento e na confecção de apresentações, na padronização dos fatos; à repetição, ao enquadramento, ao fácil e ao 'cômodo' estereótipo para o consumo do mercado. Na retórica, a interpretação é entendida como decodificação.

Ao discutir a argumentação, Ponzio a relaciona com a dialogia, afirmando que a semiótica da interpretação é fundada sobre o princípio da abertura e das aventuras dos diálogos e das argumentações. No debate, defende que a dialogicidade seja intrínseca à argumentação: "o sentido não é copiado ou desvelado, mas continuamente regenerado para ajustes argumentativos. É importante, também eticamente, ter bem presente que o sentido, na comunicação e na vida, não é e não deve ser aquilo que já existe, mas a utopia que se inventa" (BONFATINI apud PONZIO, 2012, p.133-134). Ressalva-se na conversa que, na análise dos discursos e dos textos, deve-se passar não somente da analítica à dialética, mas também da dialética à dialógica, para colher a dialogicidade específica de cada discurso" (PONZIO, 2012, p. 133).

Juntando-nos à discussão provocada por Ponzio, pensamos que se trata de evidenciar e reforçar o caráter dialógico interno dos nossos próprios pontos de vista, mostrar a ambiguidade nos significados em que repousamos nossas certezas, fazer resultar a dialogicidade interna de nossas próprias palavras. O diálogo não é uma iniciativa de sujeitos separados, mas é a própria condição do sujeito, porque é estrutural ao discurso, fato que nenhuma ideologia homologante poderá anular (PONZIO, 2012, p. 134).

O interesse do nosso estudo está voltado para a seguinte questão: como crianças em processo de alfabetização na escola, entendido com ampliação da leitura de mundo, em que se aprendem conhecimentos de diferentes áreas, explicitam por escrito novas linguagens sociais (da Ciência e da História, no nosso caso) se estão em processo de aprender?

\section{Conversando sobre a organização da argumentação nos textos infantis}

Em Goulart (2011) foram analisados cinco textos escritos por crianças de sete anos, matriculadas no segundo ano do Ensino Fundamental, quando ocorreu a culminância de um projeto que teve Piolhos como tema. Embora não possa me alongar aqui, a perspectiva é apresentar evidências de que o caminho que vem sendo aberto pode ser profícuo para continuar conhecendo 
EID\&A - Revista Eletrônica de Estudos Integrados em Discurso e Argumentação, Ilhéus, n. 12, jul/dez.2016.

os processos de ensino-aprendizagem, tendo como cenário o processo de alfabetização.

Observamos nos textos aspectos que caracterizam objetivamente 0 pilho, como em um texto científico': são insetos (texto 3); são parasitas (textos 1, 2, 4 e 5); habitam cabeça/cabelo/couro cabeludo (textos 1, 2, 3, 5); alimentam-se de sangue $(2,4,5)$; fixam-se (ao hospedeiro) (texto 1); os piolhos têm entre 0,5 e $8 \mathrm{~mm}$ de comprimento (são pequenos, portanto) (textos 1 e 5 - bichinho); referência a ovos do piolho ou lêndeas (textos 1, 2, 3 , 4, 5). Essas são evidências, portanto, de adequação na seleção de palavras e de construções sintáticas pelas crianças, revelando conhecimentos científicos nos textos analisados. Elas abordaram ainda os seguintes aspectos: os piolhos provocam coceira e ferimentos (textos 1, 2, 4, 5); transmitem/proliferam doenças (textos 1, 2, 3, 4, 5); alternativas para tratamento e higiene (textos $2 \mathrm{e}$ 5) e periculosidade (textos 1, 2, 4), são alguns destaques reunidos no ambiente escolar, onde o tema foi trabalhado.

Regularidades composicionais que caracterizam a argumentação de textos científicos escolares foram encontradas, como modos de encadeamento, além de marcas de impessoalidade, embora miscigenadas com marcas de outras esferas de atividades sociais, como a da propaganda e também a escolar. No modo de encadear os textos, a hierarquização dos argumentos sobressai, quando observamos que quatro crianças iniciam seus textos $(1,2,3,5)$ caracterizando a classe a que pertencem os animais (inseto) e/ou o modo de vida (parasita), utilizando-se de frases nominais (O piolho é um...), adjetivadas por argumentos que ampliam seus sentidos (que prejudica...; que geralmente podemos pega-los...; que vive na cabeça; que se alimenta). No texto 4, o destaque inicial é o fato de o piolho provocar coceiras, seguido de uma enumeração de outras características da vida do inseto: 0 piolho provoca coceiras, coloca ovos, cria novos piolhos, apresentando uma progressão argumentativa diferente daquela vista nos demais textos, mas o segundo momento do texto começa com a frase nominal: é um parasita, um bicho muito perigoso [...], caracterizando o piolho. O modo personalizado de apropriação das palavras de outrem é observado nas infiltrações dos comentários e réplicas dos alunos no discurso científico escolar que produzem.

\footnotetext{
${ }^{1}$ A seguir, apresenta-se, em primeiro lugar, a definição do animal; depois é indicado entre parênteses o(s) número(s) do(s) texto(s) em que há a ocorrência em destaque.
} 
EID\&A - Revista Eletrônica de Estudos Integrados em Discurso e Argumentação, Ilhéus, n. 12, jul/dez.2016.

Abaixo está, a título de ilustração, um dos textos analisados.

O Piolho

O piolho é um parasita, que geralmente podemos pega-los em comtato direto em lugares de muita aglomeração como nas escolas, ônibus, clube, e etc... $\mathrm{O}$ piolho se alimenta de sangue com isso provoca muita coceirae ferimentos em nosso couro cabeludo. Sua reprodução é feita através das lemdeas (ovos) que vão se poliferamdo em nossa cabeça. Para colbater o inimigo dervemos usar remédios ou shampoo apropriado para eleminar e comservar os cabelos sempre bem limpinho para evitar o aparecimento de novos piolhos.

Esse trabalho teve por base produções relacionadas com a área de biologia, mas atualmente estamos dando continuidade a esta investigação abordando textos de outras áreas de conhecimento, como a História. Nas primeiras investigações foi possível observar diferenças nas produções das mesmas crianças que escreveram os textos comentados acima. Vejam abaixo um dos textos em que já se evidenciam diferenças na orientação argumentativa do texto.

Índios Brasileiros

Quando o Pedro Alveres Cabral soubi o Brasil. haviam serca de 1 um milhan de ímdios no Brasil eles se devedia de tribos. os índio se iginoravam as iscreta e o fero na epoca de mil e quentos, eles sabian pescar comer, mandioca, pasoca. a unica coisa que eles gostas de ficar na redi.

A orientação argumentativa, calcada em planos temporais, se explicita de pronto, demarcando diferença em relação aos textos sobre os piolhos. 0 modo como é iniciado aponta para a dimensão temporal fundamental da linguagem social da História, entre outras que estamos em processo de analisar.

\section{Discussão}

O princípio dialógico e a categoria linguagens sociais têm sido aspectos chave para considerar como argumentativo o movimento enunciativo do discurso de diferentes áreas de conhecimento. O diálogo é considerado como o movimento e método de constituição dos discursos que historicamente vem-se organizando como linguagens sociais, ou seja, modos de estruturação dos saberes de diferentes campos do conhecimento. A compreensão de que o discurso de cada área de conhecimento se institui como uma linguagem social, ou seja, como uma forma de argumentação, historicamente formada, nos 
EID\&A - Revista Eletrônica de Estudos Integrados em Discurso e Argumentação, Ilhéus, n. 12, jul/dez.2016.

encaminhou para a proposta de pesquisar se crianças nos anos iniciais do Ensino Fundamental já apresentam no processo de aprender a escrever marcas que caracterizam diferentes linguagens sociais.

A análise que temos realizado a partir dos textos infantis escritos por crianças nos dois primeiros anos do Ensino Fundamental tem-se mostrado afirmativa no sentido de que as crianças enquanto estão se alfabetizando vão aprendendo novas formas de estruturação dos saberes, novas linguagens sociais. Não temos dúvida de que o modo de ensinar, em nosso caso, o modo de alfabetizar, provoca diferenças significativas no desempenho das crianças. Não é trivial observar crianças aos seis e sete anos escrevendo textos como os apresentados. Assim, os resultados têm nos animado a dar continuidade à pesquisa, mantendo como eixo o pressuposto de que enunciar é argumentar.

\section{Referências}

BAKHTIN, Mikhail; VOLOCHINOV, Valentin. Marxismo e Filosofia da Linguagem. 4. ed. Trad. Michel Lahud e Yara F. Vieira. São Paulo: HUCITEC, 1988.

BAKHTIN, Mikhail. Estética da criação verbal. Trad. Maria Ermantina Galvão G. Pereira. São Paulo: Martins Fontes, 1992.

- Questões de literatura e de estética: a teoria do romance. Trad. Aurora Fornoni Bernadini et alii. São Paulo: HUCITEC/ UNESP, 1998.

- The Dialogic Imagination. Editado por Michael Holquist. 14. ed. Austin: University of Texas Press, 1981.

- Dialogic Origin and Dialogic Pedagogy of Grammar. Stylistics in Teaching Russian Language in Secondary School. Journal of Russian and East European Psychology, v. 42, n. 6, p. 12-49, 2004.

GOULART, Cecilia M. A. Linguagens sociais e argumentação: investigando modos de letrar e ser letrado. Seminário Dialogismo Bakhtiniano: interlocuções com a linguística, a psicologia e a educação. Curso de Pós-Graduação em Psicologia, Núcleo de Pesquisa em Argumentação, UFPE, junho de 2005.

. Enunciar e argumentar: analisando um episódio de uma aula de História com base em Bakhtin. Pro-posições, v. 18, n. 3 (54), p. 93-107, set/dez 2007.

. Em busca de balizadores para a análise de interações discursivas com base

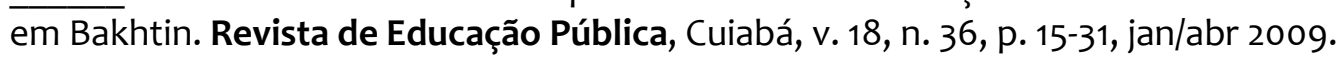


EID\&A - Revista Eletrônica de Estudos Integrados em Discurso e Argumentação, Ilhéus, n. 12, jul/dez.2016.

. Processos escolares de ensino e aprendizagem, argumentação e linguagens sociais. Revista Bakhtiniana, São Paulo, v. 1, n. 4, p. 50-62, 2010.

GOULART, Cecilia M. A. Alfabetização, discurso científico e argumentação. In: LEITÃO, Selma; DAMIANOVIC, Maria Cristina. Argumentação na escola: o conhecimento em construção. São Paulo: Pontes, 2011. p. 129-151.

HOLQUIST, Michael. Dialogism. Bakhtin and his world. 2. ed. London; New York: Routledge, 2004.

MORRISON, Ken. Estabelecendo o texto: a institucionalização do conhecimento por meio das formas históricas e filosóficas de argumentação. In: BOTTÉRO, J. et al. Cultura, Pensamento e Escrita. São Paulo: Ática, 1995. p. 141-200.

PONZIO, Augusto. Dialogando sobre diálogo na perspectiva bakhtiniana. São Carlos: Pedro \& João Editores, 2012.

POSSENTI, Sírio. Enunciação, autoria e Estilo. Revista Brasileira da FAEEBA, Salvador, n. 15, p. 15-21, jan./jun. 2001.

STOCK, Brian. The Implications of Literacy: Written language and models of interpretation in the eleventh and twelfth centuries. Princeton: Princeton University Press, 1983.

Forma de citação sugerida:

GOULART, Cecília Maria Aldigueri. Argumentação e aprendizagem da escrita na escola. EID\&A - Revista Eletrônica de Estudos Integrados em Discurso e Argumentação, Ilhéus, n. 12, p. 53-63, jul/dez.2016.

Recebido em: 27/10/2016

Aprovado em: 08/12/2016 